This item was submitted to Loughborough's Research Repository by the author.

Items in Figshare are protected by copyright, with all rights reserved, unless otherwise indicated.

\title{
Understanding values diversity within the organisation: a case study in UK
} Construction

PLEASE CITE THE PUBLISHED VERSION

LICENCE

CC BY-NC-ND 4.0

\section{REPOSITORY RECORD}

Zhang, Xiaoxing, Simon A. Austin, and Jacqueline Glass. 2019. "Understanding Values Diversity Within the Organisation: A Case Study in UK Construction”. figshare. https://hdl.handle.net/2134/5072. 
This item was submitted to Loughborough's Institutional Repository (https://dspace.lboro.ac.uk/) by the author and is made available under the following Creative Commons Licence conditions.

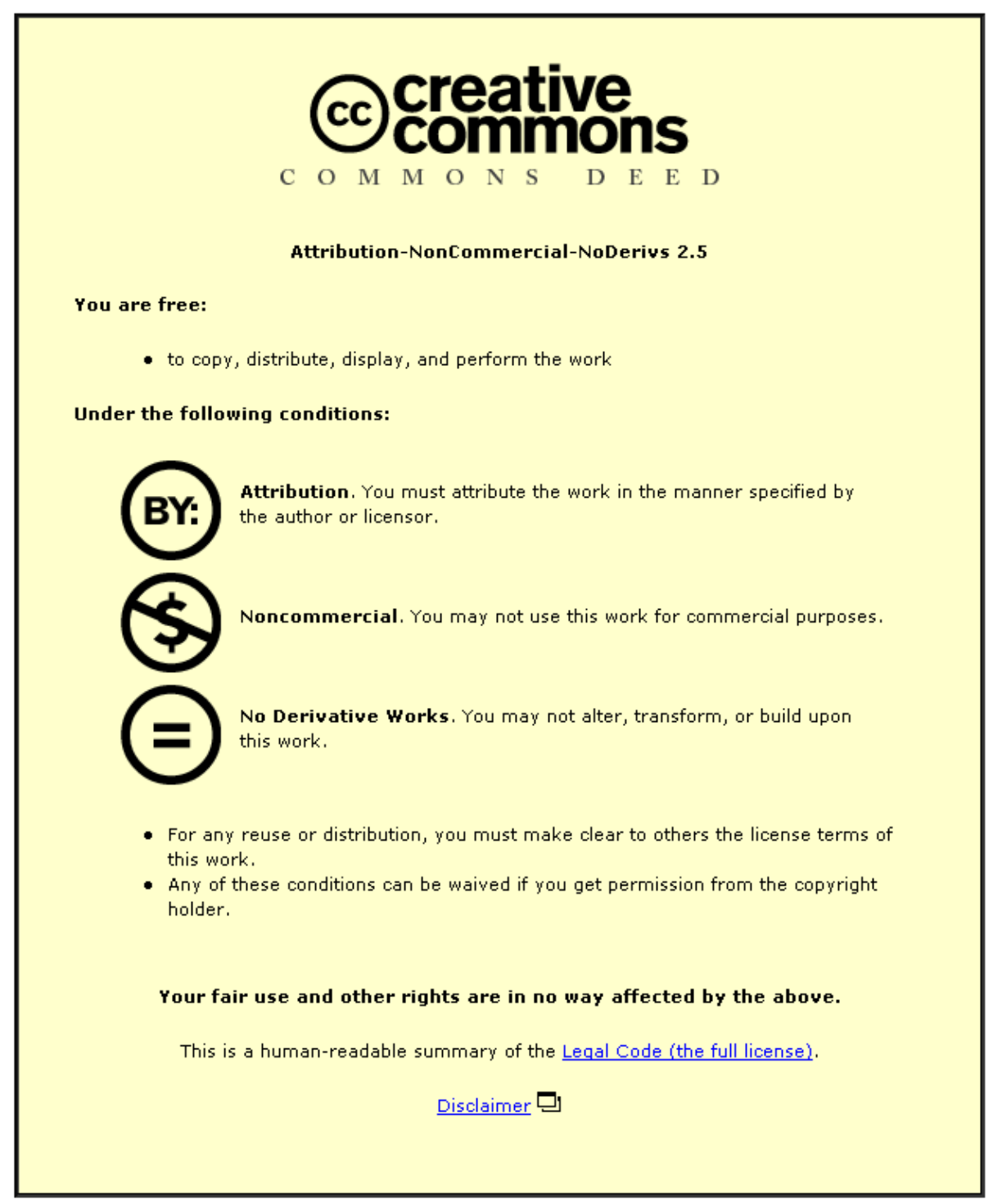

For the full text of this licence, please go to: http://creativecommons.org/licenses/by-nc-nd/2.5/ 


\title{
Understanding values diversity within the organisation: A case study in UK construction
}

Xiaoxing Zhang, Simon A Austin and Jacqueline Glass Loughborough University, UK

\begin{abstract}
Any increasing diversity in a workforce necessitates a better understanding of individual and team differences in the organisation, as well as how such differences affect the organisation itself. Previous research has highlighted that diversity in people's values will have consequences for an organisation, and is therefore critical in the area of diversity management. Nevertheless, understanding values diversity within the organisation is not an easy task. The difficulties are exacerbated by the dearth of literature offering practical guidance. The case study presented has been conducted in a UK construction company using Schwartz's theoretical framework of human values as a framing device. Employees' values profiles were collected and analysed through an organisational-wide survey. The process helped identify shared values, and highlighted differences between various sub-groups. It made the divergence of values explicit, thus facilitating mutual understanding within the organisation. It is argued that values diversity should be encouraged and respected within a collectivistic culture, enabling a heterogeneous workforce to work harmoniously toward their common goals, maximising the contribution of each member, and ensuring fair treatment for all irrespective of background. In addition, Schwartz's circumplex model of values and its associated survey instrument are helpful framing devices to reveal values diversity and facilitate values communication within the organisation.
\end{abstract}

Key words: Case study, Diversity, Organisation, Survey, Values. 


\section{NTRODUCTI ON}

During the 21st century, an important trend affecting the workforce is the increasing diversity (Lavaty and Kleiner, 2001), which is a phenomenon that has a wide array of effects within the workplace and society in general (Koonce, 2001; Stark, 2001; Williams and O'Reilly, 1998). In order to create an organisational environment that allows employees to reach their full potential in pursuing the organisational goals, many academics and practitioners agree that organisations should aim to manage diversity effectively rather than simply value it or rely on affirmative action policies (Sadri and Tran, 2002). This necessitates a better understanding of individual and team differences in the organisation, as well as how such differences affect the organisation itself.

Research examining diversity within the organisation has often focused on the surface-level, e.g. demographic diversity among the workforce. However, the deep-level, i.e. values diversity, is claimed to have significant consequences for an organisation (Harrison et al., 1998; Jehn et al., 1999; Owens and Neale, 1999), is therefore of importance and requires specific attention. Nevertheless, understanding employees' values difference is not an easy task. The difficulties are exacerbated by the dearth of literature offering practical guidance.

The case study presented has been conducted in a UK construction company using Schwartz's theoretical framework of human values as a framing device. Through an organisational-wide values survey, employees' values profiles were collected, analysed, presented and debated. The study helped identify shared values, and highlighted the diversity between various sub-groups. This approach it offers a viable method for exploring and managing values diversity within the organisation.

\section{VERSI TY MANAGEMENT}

Diversity management is a strategic business issue for many organisations (Dodds, 1995). It emerged in the USA (Kandola and Fullerton, 1994; Wilson and Iles, 1999) and became very influential in the UK in the 1990s (Mavin and Girling, 2000; Seymen, 2006).

\section{Definitions of diversity}

Diversity can be defined as a mixture of people with different group identities within the same social system (Fleury, 1999). It refers to any attribute that 
happens to be salient to an individual that makes him/her perceive that he/she is different from another individual (Williams and O'Reilly, 1998). Patterson (1990) defines it as the 'state of being diverse, that is, different, unlike, various'. Cox (1993, p.6) expresses diversity in broad terms as 'a mix of people in one social system who have distinctly different, socially relevant group affiliations'. Further, Thomas (1996) suggests that diversity relates to everybody and is multidimensional. He considers diversity as a mixture of visible differences (e.g. race, gender, or age) and less visible differences (e.g. educational levels, sexual orientation, ways of thinking, or personal values and belief systems) (Thomas, 1991).

These definitions make it clear that diversity is a broad concept which encompasses many sources of differences within one social system. The may include culture, race, geographic origin, ethnicity, gender, nationality, functional or educational background, physical and cognitive capability, language, lifestyles, values and beliefs, sexual orientation, physical abilities, social class, age, socioeconomic status, and religion (Dessler, 1998; Ferdman, 1995).

\section{Diversity management in the workplace}

In the workplace, the effects of diversity among team members have been shown to impact upon many aspect of work, especially work-related behaviours and outcomes. Over the years this has attracted much attention from both academics and practitioners.

Perspectives on workforce diversity vary. Proponents believe that dissimilarities between individuals give rise to varied ideas, perspectives, knowledge and skills which can lead to greater creativity and innovation, improved decision-making and problem solving (Chatman et al., 1998; Cox, 1991; Mannix and Neale, 2005). This position is supported by a number of empirical studies (e.g. Ely and Thomas, 2001; Jehn et al. 1999; Watson et al., 1993).

Conversely, sceptics see diversity as a problem and a difficult issue to manage. They believe that the biases between individuals may result in breakdowns in communication, decreased group integration and collaboration, and higher turnover (Brickson, 2000; Cox, 1991; Gratton and Erickson, 2007). Hopkins et al. (1994) also suggest that rapid and significant increases in work force diversity will also result in a high degree of value incongruence.

The debate between these contrasting viewpoints leads to another stream of thought which suggests that diversity is a double-edged sword. In some tasks it 
can help improve group performance, but in other cases disrupt group processes (Guzzo and Dickson, 1996; Milliken and Martins, 1996; Pelled et al., 1999).

The above viewpoints delineate some of the difficulties and potential benefits of a diverse workforce, and highlight the importance of effective diversity management in the workplace. Some define the term 'diversity management' as ensuring that all people maximise their potential (Kandola and Fullerton, 1994; Kandola, 1995; McDougall, 1996). Others give detailed definitions within an organisational context. Bartz et al. (1990, p. 321) consider it involves 'understanding that there are differences among employees and that these differences, if properly managed, are an asset to work being done more efficiently and effectively'. Ivancevich and Gilbert (2000, p. 75 ) refer it to 'the systematic and planned commitment by organisations to recruit, retain, reward, and promote a heterogeneous mix of employees'. According to Cornelius et al. (2000), managing diversity means recognise the worker's individuality and believe in the benefits of diversity to the organisation.

Therefore, diversity management is a business strategy that aims to benefit from a diverse workforce by effectively managing the differences among employees. Those interested in this topic have focused on the relationship between diversity and work group performance. It is through these research studies that the importance of understanding values diversity in the organisation is highlighted.

\section{Values diversity}

Investigations of diversity and work group performance have largely been "black box" studies (Lawrence, 1997), which fail to measure intervening process variables. Williams and O'Reilly (1998) reviewed 40 years of diversity research and concluded that there are no consistent, identifiable effects of diversity on organisational performance. They proposed that a more complex framework and conceptualization of the nature of diversity are needed to study the impact of diversity.

Some theorists have agreed to describe diversity using readily detectable attributes (e.g. race/ethnicity, sex, age), i.e. surface level diversity and underlying, deep level diversity (e.g., attitudes, values) (Jackson et al, 1995; Milliken and Martins, 1996). Harrison et al (1998) argue that the length of time group members work together weakens the effects of surface-level diversity and strengthens the effects of deep-level diversity as group members have the opportunity to engage in meaningful interaction. 
Further, Jehn et al. (1999) classified diversity into three categories: informational, social category and value diversity. From a field study of 92 workgroups, they explored the influence of these three types and found that, whilst informational diversity positively influenced group performance, and social category diversity positively influenced group member morale, value diversity decreased satisfaction, intent to remain, commitment to the group and can lead to task, process and relationship conflicts. They therefore claim that 'value diversity, although often not immediately discernible, becomes more important as a predictor of group performance over time, while age and gender diversity, characteristics that are readily apparent, become less relevant over time'. Hence 'it is the diversity associated with values, and not social category, that causes the biggest problems in and has the greatest potential for enhancing both workgroup performance and morale'. Similarly, Owens and Neale (1999) conducted a study of research and development teams, and the results reinforce the importance of low value diversity on workgroup performance over time.

All of this supports the proposition that to assess a group's diversity perspective, researchers should aim to assess not only the group's externally discernible characteristics, but more importantly, those internally enacted values and beliefs as well (Barley, 1991; Martin, 1992; Schein, 1984). Unfortunately, these values often remain concealed or unconscious, and tend not to be communicated within organisations. Managers and employees of many organisations are often unaware of the values they and their colleagues possess and may tend to misjudge them, which can cause friction and introduce tensions at work.

The aim of this exploratory study is to present the process and findings of a values study conducted in all the UK offices of a global construction management services organisation. Employees' values similarities and differences were revealed through a questionnaire survey based on Schwartz's values framework. It made the similarities and divergence of values explicit, thus offering a means to facilitate the management of values diversity.

\section{CASE STUDY}

\section{THE ORGANI SATI ON}

The study was conducted in all UK offices of a global construction management services organization. The recent change from partnership to Limited Liability Company challenged the company to establish a cultural identity compatible with its new legal status, and offered opportunities to set a vision for its future. The 
senior management set out the intention to adopt values-based management by identifying a set of authentic organisational values that are formulated around the commonly held values of the employees. An organisation-wide values study was conducted (see Zhang et al, 2008), through which the similarities and differences of employees' personal values were identified, and values diversity within the organisation analysed.

\section{THEORETI CAL FRAMEWORK}

This study examined values through the lens of Schwartz's values theory (Schwartz, 1992). Based on universal requirements of human existence, and from samples of more than 60,000 individuals from over 60 nations, this theory identifies ten motivationally-distinct values as shown in Figure 1. Schwartz (1992) proposed a circumplex model, which addresses the dynamics of conflict and congruence among these values. He pointed out that adjacent value types are postulated to be most compatible, and a greater distance between values types indicates decreasing compatibility and greater conflict. The ten categories could be grouped into four higher order groups, which demonstrate two bi-polar dimensions, where 'openness to change' contrast to 'conservation' values, and 'self-transcendence' contrast to 'self- enhancement' values.

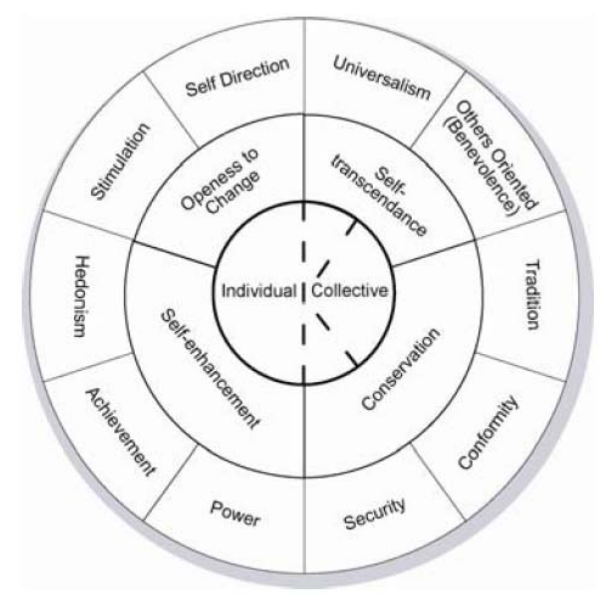

Figure 1 A universal values system/ structure adapted from Schwartz (1992) (Source: Mills et. al., 2006)

\section{METHOD}

The questionnaire was adapted from the Schwartz Values Survey (SVS) (Schwartz, 1992) which measures individuals' opinions of the relative importance of 56 generic values. Respondents were asked to indicate, using a nine-point Likert scale from - 1 to 7, the importance of each item in their lives. Respondents were also asked to rate one supremely important value 7 and one least important 
value $-1,0$ or 1 on each sheet before rating other items. This anchored the response scale thus enable values to be assessed independently of one another.

A scale-use correction process were undertaken using the individual's mean rating of all value items as a covariate to center each participant's responses (Schwartz and Littrell, 2007). These centered value scores (CVS), rather than the raw scores, were then used in the analysis.

\section{VALUES SURVEY RESULTS AND DISCUSSI ON}

The questionnaire was sent to every UK employee of the company (456 in total) based in its 16 UK offices in mid-2005 and anonymous responses returned for confidential analysis. A total of $411(90 \%)$ responses were retained for analysis.

To examine and interrogate the survey results, the CVS of each respondent, the mean CVS and standard deviation across the whole organisation were plotted in a radar diagram (Figure 2). These were emailed to each participant with notes to facilitate understanding. Many employees found the chart informative. It not only enabled them to visualize their own values and identify the interrelationships between these values items, but also facilitate the comparison between their personal values and those of the organisational average. It effectively engaged employees in a values dialogue and activated people's values within the organisational context.

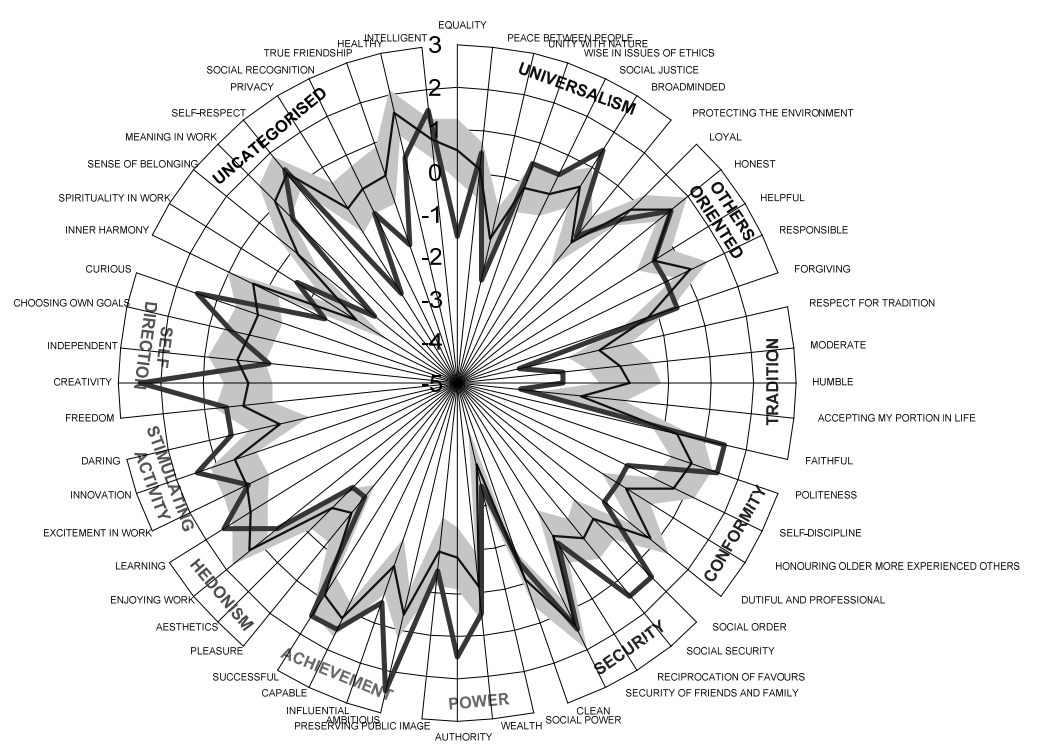

Standard Deviation

- Participant 009

口 Organisational Average

Figure 2 Example of an individual's values chart

Data analysis revealed the values priority and consensus among organisational members. The mean CVS of Schwartz's high-level values categories are calculated and presented in Figure 3. 


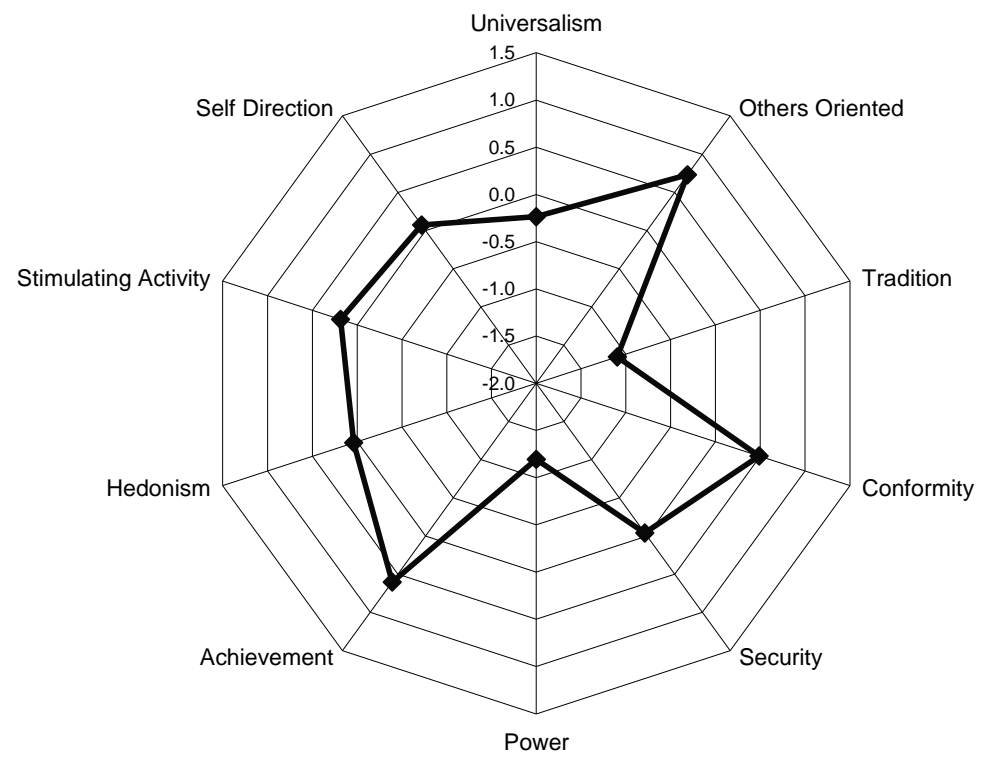

Figure 3 Organisational mean CVS of values categories

Figure 3 suggests that within the organisation, there was a substantially more positive feeling about 'Others Oriented', 'Achievement' and 'Conformity' values, together with a considerably negative feeling about 'tradition' and 'power'. Revealing these organisational values priorities helped the employees to understand their shared values and generated a sense of responsibility to ensure that values were identified, understood, integrated and 'lived'. The values perceived as of high priority across the organisation were discussed in six followup workshops and evolved into a set of organisational values (Zhang et al, forth coming). This enhanced values congruence within the organisation, where individual values coincide with values at the organisational level.

Further analyses investigated the differences between various sub-groups (see Table 1 for examples). Due to some respondents chosing not to provide certain background information, the responses range from 362 to 381 (80 to 84 percent). The mean CVS of groups were calculated and one-way analysis of variance test (ANOVA) revealed the statistic significance of the results and hence major differences.

The variations across the age groups were analysed through an ANOVA. Whilst these age groups possess similar views towards 'universalism', 'other oriented', 'conformity', 'achievement' and 'self direction', statistically significant differences were found in the values categories listed in Table 2. It appeared that the older employees (>55 years old) gave a significantly lower score to "hedonism', 'power' and 'stimulating activity' than their younger colleagues, and gave much higher scores to 'tradition' than the 26-35 age group. Older groups also generally 
consider 'hedonism' of less importance than the younger groups, indicating they are not very open to changes and have less interest in self-enhancement.

Meanwhile, the youngest (under 26 years old) and oldest (above 55 years old) groups give a much higher score to 'tradition' than those between 26 and 35 . Whilst it is understandable that older people would generally like to stick with traditions, the relatively higher scores among those under 26 years old is interesting. Further discussion in a follow-up workshop revealed that young people are curious about what happened in the past and it is the mysteriousness that attracts their attention. Furthermore, 'security' is of greater importance to staff aged 36 to 55 than those between 26 and 35. One explanation is that most people in 36 to 55 age group have well established family and career, and they are keen to protect these from any risks.

Table 1 Sample characteristics of the analysis

\begin{tabular}{l|c|c}
\hline \multicolumn{1}{c|}{ Categories } & $\begin{array}{c}\text { Number of Responses } \\
\text { analysed }\end{array}$ & $\begin{array}{c}\text { Percentage within } \\
\text { organisation }\end{array}$ \\
\hline Age & 32 & $7 \%$ \\
$<26$ years of age & 105 & $23 \%$ \\
$26-35$ years of age & 179 & $39 \%$ \\
$36-55$ years of age & 62 & $14 \%$ \\
$>55$ years of age & 86 & $19 \%$ \\
\hline Gender & 293 & $64 \%$ \\
Female & 27 & $6 \%$ \\
Male & 27 & $6 \%$ \\
Management Level & 48 & $11 \%$ \\
Directors & 280 & $61 \%$ \\
Divisional Directors & & $70 \%$ \\
Associates & 319 & $20 \%$ \\
Others & 92 & $17 \%$ \\
Geographical Location & 78 & $41 \%$ \\
UK North & 187 & $4 \%$ \\
UK South & 20 & $17 \%$ \\
\hline Professional Discipline & 77 & \\
Project Manager & & \\
Cost Manager & & \\
Management Consultant & & \\
Others & & \\
\hline
\end{tabular}

Table 2 Significant differences between age groups

\begin{tabular}{|c|c|c|c|c|c|c|}
\hline $\begin{array}{c}\text { Values } \\
\text { categories }\end{array}$ & $\begin{array}{c}\quad F \\
(3,374)\end{array}$ & $p(<0.05)$ & $\begin{array}{c}\text { Eta } \\
\text { Squared }\end{array}$ & $\begin{array}{c}\text { Group with } \\
\text { significantly high } \\
\text { score }\end{array}$ & $\begin{array}{c}\text { Group with } \\
\text { significantly low } \\
\text { score }\end{array}$ & $\begin{array}{c}\text { Score } \\
\text { difference }\end{array}$ \\
\hline \multirow{3}{*}{ Hedonism } & \multirow{3}{*}{5.204} & \multirow{3}{*}{0.002} & \multirow{3}{*}{0.04} & $<26$ & $>55$ & 0.4 \\
\hline & & & & $26-35$ & $>55$ & 0.3 \\
\hline & & & & $26-35$ & $36-55$ & 0.2 \\
\hline \multirow{2}{*}{ Tradition } & \multirow{2}{*}{4.474} & \multirow{2}{*}{0.004} & \multirow{2}{*}{0.04} & $<26$ & $26-35$ & 0.4 \\
\hline & & & & $>55$ & $26-35$ & 0.3 \\
\hline \multirow{2}{*}{ Power } & \multirow{2}{*}{4.198} & \multirow{2}{*}{0.006} & \multirow{2}{*}{0.03} & $36-55$ & \multirow{2}{*}{$>55$} & 0.5 \\
\hline & & & & $26-35$ & & 0.5 \\
\hline $\begin{array}{l}\text { Stimulating } \\
\text { Activity }\end{array}$ & 3.768 & 0.011 & 0.03 & $26-35$ & $>55$ & 0.4 \\
\hline Security & 2.969 & 0.032 & 0.02 & $36-55$ & $26-35$ & 0.2 \\
\hline
\end{tabular}


The differences between female and male employees' values perception are shown in Figure 4 and Table 3. Generally speaking, the mean scores of the two groups display trends. However, as shown in Figure 4, value items related to 'openness to change' and 'self-enhancement' are, with some exceptions, valued higher by male employees. Conversely, the values related to self-transcendence and conservation are more favoured by females. Table 3 also shows that male employees gave significantly higher scores to 'power' than the females, while female employees score 'universalism' and 'conformity' higher than their male colleagues. However, as evident in small effect size (eta squared values range from 0.01 to 0.03 ), these differences are not as significant as those between other groups, which suggests that values differences between gender groups are minimal. This findings support Schwartz's hypothesis that the correlations between values and gender are very weak (Schwartz et al., 2001).

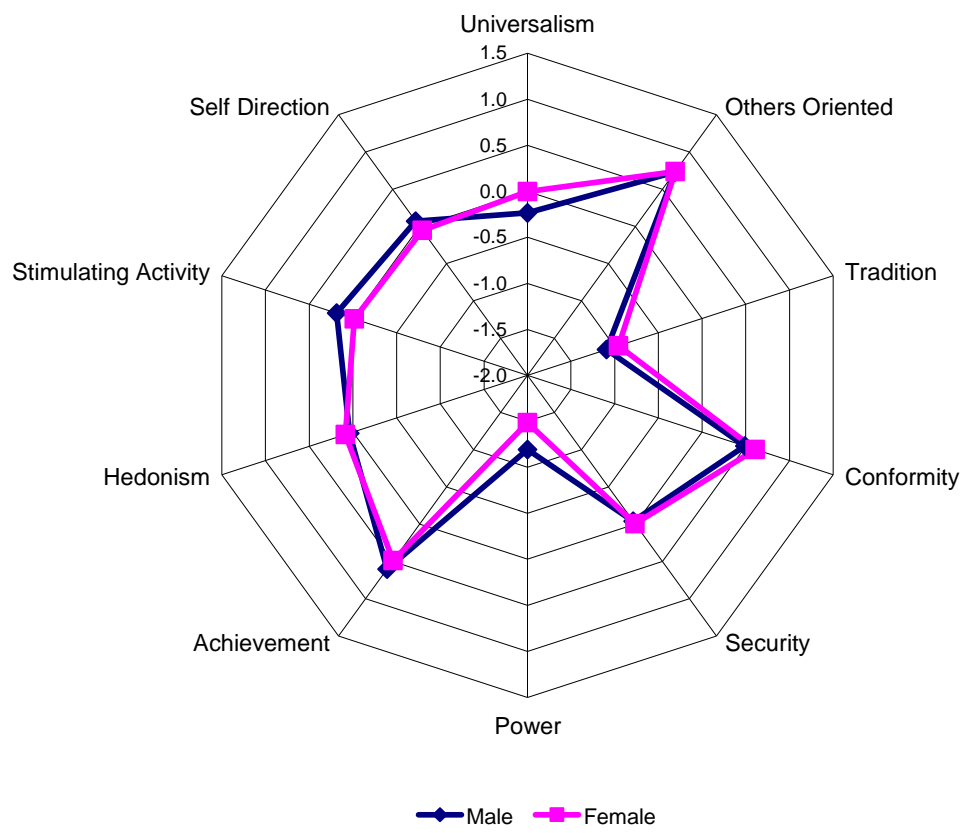

Figure 4 Values differences between genders

Table 3 Significant differences between genders

\begin{tabular}{l|c|c|c|c|c|c}
\hline $\begin{array}{c}\text { Values } \\
\text { categories }\end{array}$ & $\begin{array}{c}\mathbf{F} \\
\mathbf{( 1 , 3 7 7 )}\end{array}$ & $\mathbf{p ~ ( < \mathbf { 0 . 0 5 ) }}$ & $\begin{array}{c}\text { Eta } \\
\text { Squared }\end{array}$ & $\begin{array}{c}\text { Group with } \\
\text { significantly high } \\
\text { score }\end{array}$ & $\begin{array}{c}\text { Group with } \\
\text { significantly low } \\
\text { score }\end{array}$ & $\begin{array}{c}\text { Score } \\
\text { difference }\end{array}$ \\
\hline \hline Power & 13.171 & 0.000 & 0.03 & Male & Female & 0.4 \\
\hline Universalism & 11.725 & 0.001 & 0.03 & Female & Male & 0.3 \\
\hline Conformity & 4.390 & 0.037 & 0.01 & Female & Male & 0.2 \\
\hline
\end{tabular}

The differences between directors and other staff, as shown in Table 4, reveal some interesting facets. The top two levels of management (directors and divisional directors) have very similar priorities. This may be related to how the senior managers were selected within the organisation. Whilst all the groups gave 
very similar scores to 'security' and 'others oriented' values, the major differences emerge between the senior managers and other staff, with the middle management, i.e. associates, aligning with one or the other. As shown in Table 4, the managers gave significantly higher scores on 'achievement' than the other staff $(P<0.0005)$. The effect size eta squared values is 0.09 , which in Cohen's (1988) terms would be considered a medium effect size. With a large enough sample (in this case $\mathrm{N}=381$ ), this difference can be considered as significant.

Similarly, compared with other staff and/or the associates, the senior managers gave significantly higher scores to 'stimulating activity' and 'power' and significantly lower score to 'conformity' in comparison to other staff. This indicates that the senior managers are generally more open to change and focusing on self enhancement, whilst other staff are more conservative. According to Sosik (2005), managers who display charismatic leadership grounded in openness to change, collectivistic work, and self-enhancement values can promote extra effort and extra role performances that fully engage employees.

Although the findings in this organisation seems to be positive in terms of managerial values, it should also be noted that some managers may claim some values to be important but fail to integrate them in their behaviours. Therefore, it is very important that managers should possess and act upon these values in an authentic manner. Overall, revealing these management level differences will facilitate mutual understanding between the managers and their staff, and form a base to shape the company's strategic management in the future.

Table 4 Significant differences between management levels

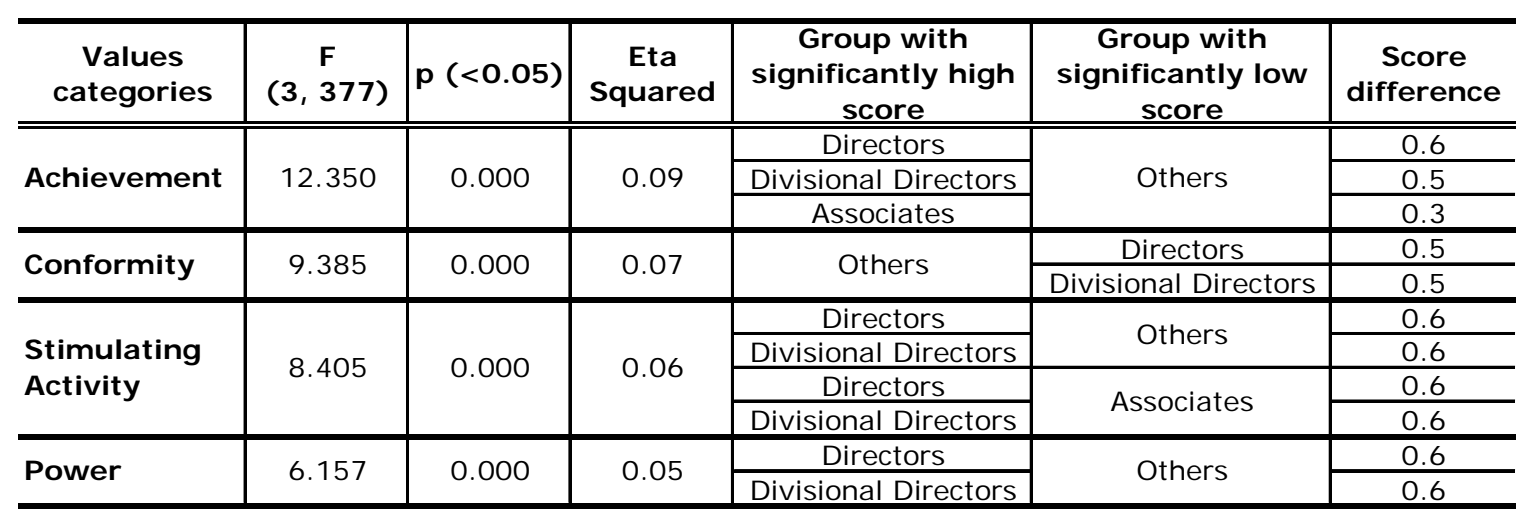

In the UK, there seems to be a North-South divide which often refers to the economic and cultural differences between southern and northern parts of the country. To investigate the values differences between these two broad geographical zones, data from the UK south offices and the UK north offices we compared (see Table 5). It appeared that UK North office staff rated 'tradition' 
much higher than UK South office staff and rated 'power' much lower than UK South. However, while the differences exist, the effect size was small, which demonstrates that the geographical differences are not as significant as those associated with age and management level.

Table 5 Significant differences between geographical zones

\begin{tabular}{|c|c|c|c|c|c|c|}
\hline $\begin{array}{c}\text { Values } \\
\text { categories }\end{array}$ & $\begin{array}{c}F \\
(1,409)\end{array}$ & $p(<0.05)$ & $\begin{array}{c}\text { Eta } \\
\text { Squared }\end{array}$ & $\begin{array}{c}\text { Group with } \\
\text { significantly high } \\
\text { score }\end{array}$ & $\begin{array}{c}\text { Group with } \\
\text { significantly low } \\
\text { score }\end{array}$ & $\begin{array}{c}\text { Score } \\
\text { difference }\end{array}$ \\
\hline Tradition & 10.529 & 0.001 & 0.03 & UK North & UK South & 0.3 \\
\hline Power & 5.314 & 0.022 & 0.01 & UK South & UK North & 0.2 \\
\hline
\end{tabular}

As a multi-disciplinary company, identifying the values differences between people from different professional background could be useful in harmonizing the teamwork. There are four major groups within the organisation, i.e. project managers, cost managers, management consultants and supporting staff (e.g. administrators, accountants and IT technicians). As shown in Table 6, statistical analysis revealed that the two dominant groups, PM and CM, rated 'power' much higher than supporting staff, and 'universalism' much lower.

Table 6 Significant differences between professional disciplines

\begin{tabular}{|c|c|c|c|c|c|c|}
\hline $\begin{array}{c}\text { Values } \\
\text { categories }\end{array}$ & $\begin{array}{c}\quad F \\
(3,358)\end{array}$ & $p(<0.05)$ & $\begin{array}{c}\text { Eta } \\
\text { Squared }\end{array}$ & $\begin{array}{c}\text { Group with } \\
\text { significantly high } \\
\text { score }\end{array}$ & $\begin{array}{c}\text { Group with } \\
\text { significantly low } \\
\text { score }\end{array}$ & $\begin{array}{c}\text { Score } \\
\text { difference }\end{array}$ \\
\hline \multirow{2}{*}{ Power } & \multirow{2}{*}{3.372} & \multirow{2}{*}{0.019} & \multirow{2}{*}{0.04} & Project Managers & \multirow{2}{*}{ Others } & 0.5 \\
\hline & & & & Cost Managers & & 0.4 \\
\hline \multirow{2}{*}{ Universalism } & \multirow{2}{*}{3.089} & \multirow{2}{*}{0.028} & \multirow{2}{*}{0.03} & \multirow{2}{*}{ Others } & Cost Managers & 0.3 \\
\hline & & & & & Project Managers & 0.3 \\
\hline
\end{tabular}

In summary, the above analysis demonstrates that, whilst gender and geographical differences are minimal, significant age and discipline differences were found within the organisation. Even greater differences were found between different management level groups. Across all these subgroups, no significant differences were found in 'self direction' and 'others oriented' values. However, the groups did have significantly different views on the values category of 'power'. Male employees, working as project managers or cost managers, aged between 26 and 55, senior managers and those from UK south, considered 'power' of much greater importance than their colleagues.

By revealing these similarities and differences of employees' values proposition, the research helped establish a useful platform for future diversity management. Employees were encouraged to focus on the values that are of high priority across the organisation so that a truly collectivistic culture could be established. Under this umbrella, values differences found between subgroups provide valuable information to facilitate mutual understanding between individuals and groups. This could help reduce the level of conflict and allow the organisation to 
benefit from the differences of cultures, experiences and ideas. However, it is worth noting that the emphasis should always be on the commonly shared values rather than the values differences among employees, so that the employees are able to stay focused on what is important instead of worrying about how they are different to one another. We agree with McMillan-Capehart (2005, p.498) that the collectivistic culture is 'the overall guiding power that allows diversity to result in positive outcomes'. By implementing individualistic socialization tactics within a collectivistic culture, organisations can benefit from employees' backgrounds and experiences, while promoting teamwork and a cohesive organisation.

In addition, the results enabled senior management to recognize the particular priorities among the employees, which revealed some root causes of existing conflicts, and informed future business strategies, such as team formation and collaboration, recruitment and promotion, and employee care and development. Indeed, the more we know about these values priorities and differences, the easier it is to understand and accommodate them within the organisation, which would lead to positive impacts on levels of motivation and job satisfaction among individuals, and hence the improvement in business performance.

\section{CONCLUSION}

Given that individuals are unlikely to be willing to leave their differences outside the doors of the workplace (Thomas, 1991), an organisation's ability to systemically manage diversity is clearly important, particularly in the current business environment where a diverse workforce is almost unavoidable. Previous research has highlighted that managing values diversity, inter alia, is crucial in diversity management. We have argued that this requires a thorough understanding of personal values before they can be communicated, compared and effectively managed. The case study presented here offers a way to reveal employees' values similarities and divergence within the organisation through a structured method derived from Schwartz's values theory. Understanding values diversity within the organisation could enable the heterogeneous workforce to work together harmoniously toward their common goals, maximise the contribution of each member, and ensure fair treatment for all irrespective of background.

In addition, it has been made clear that Schwartz's circumplex model of values and associated survey instrument are helpful framing devices to reveal values diversity and facilitate the communication of values within the organisation. A systematic and fine-grained analysis of human values helped raise awareness in 
terms of values priority, values diversity and the interrelationships between these values, and the approach described appears to be an effective instrument in managing values diversity.

Nevertheless, there are limitations to this study. The mostly positive-sounding value categories could create bias because respondents may be inclined to choose a utopian answer which is not reflected in their behaviours. The anchoring of the response scale partly addresses this, and the confidentiality of the questions would mitigate against this, but further consideration of possible biases is necessary. In addition, the single company nature of the study precludes any conclusions about the expansion of the findings to the broader industry.

Values diversity is a contentious but important subject of debate in diversity management. This study offered one avenue to move towards effective values diversity management in the workplace. By revealing the similarities and differences of employees' values proposition and establish a collectivistic culture based on employees shared values, a 'diversity friendly' environment could be created which would benefit the organisation in the long term. 


\section{REFERENCES}

Bartz, D. E., Hillman, L. W., Lehrer, S. and Mayhugh, G. M. (1990) A model for managing workforce diversity. Management Education and Development, Vol. 21 No. 5, pp. 321-6.

Brickson, S. (2000) The impact of identity orientation on individual and organisational outcomes in demographically diverse settings. Academy of Management Review, Vol. 25 No. 1, pp. 82-101.

Chatman, J. A., Polzer, J. T., Barsade, S. and Neale, M. A. (1998) Being different yet feeling similar: The influence of demographic composition and organisational culture on work processes and outcomes. Administrative Science Quarterly, 43, pp.749-780.

Cornelius, N., Gooch, L. and Todd, S. (2000) Managers leading diversity for business excellence. Journal of General Management, Vol. 25 No. 3, pp. 6778.

Cox, T. (1991) The multicultural organisation. Academy of Management Executive, Vol. 5 No. 2, pp. 34-47.

Cox, T. (1993) Cultural Diversity in Organisations: Theory, Research, and Practice. Berrett-Koehler, San Francisco, CA.

Daft, R. L. (2003) Management (6th Eds). Thomson Learning, London.

Dessler, G. (1998) Management: leading people and organisations in the 21st century. Prentice-Hall, Inc., New Jersey, NJ .

Dodds, I. (1995) Differences can also be strength. People Management, 20 Apr, 1995, pp. 40-43.

Ely, R. J., and Thomas, D. A. (2001) Cultural diversity at work: The effects of diversity perspectives on work group processes and outcomes. Administrative Science Quarterly, 46, pp. 229-273.

Ferdman, B. M. (1995) Culture identity and diversity in organisations: bridging the gap between group differences and individual uniqueness. In Chemers, M. M., Oskamp, S. and Costanzo, M. A. Eds, Diversity in Organisations: New Perspectives for a Changing Workplace. Sage, Thousand Oaks, CA, pp. 37-61.

Fleury, M.T.L. (1999) The management of culture diversity: lessons from Brazilian companies. Industrial Management \& Data Systems, Vol. 99 No. 3, pp. 10914. 
Gratton, L. and Erickson, T. J. (2007) Eight ways to build collaborative teams. Harvard Business Review, Nov 1, 2007.

Guzzo, R. A., and Dickson, M. W. (1996) Teams in organisations: Recent research on performance and effectiveness. Annual Review of Psychology, 47, pp. 307338.

Harrison, D. A.; Price, K. H. and Bell, M. P. (1998) Beyond relational demography: Time and the effects of surface- and deep-Level diversity on work group cohesion. The Academy of Management Journal, Vol. 41 No. 1, pp. 96-107.

Hopkins, W., Sterkel-Powell, K. and Hopkins, S.A. (1994) Training priorities for a diverse workforce. Public Personnel Management, Vol. 23 No. 3, pp. 429-436.

Ivancevich, J. M. and Gilbert, J. A. (2000) Diversity management: time for a new approach. Public Personnel Management, Vol. 29 No. 1, pp. 75-92.

Jackson, S.E., May, K.E., Whitney, K. (1995) Understanding the dynamics of diversity in decision-making teams. In Guzzo, R. A. and Salas, E. (Eds.), Team decision-making effectiveness in organisations, pp. 204-261. San Francisco: Jossey- Bass.

Jehn, K. A., Northcraft, G. B. and Neale, M. A. (1999) Why some differences make a difference: A field study of diversity, conflict, and performance in workgroups. Administrative Science Quarterly, 44, pp. 741-763.

Kandola, R. (1995) Selecting for diversity. International Journal of Selection and Assessment, Vol. 3 No. 3, July.

Kandola, R. and Fullerton, J. (1994) Managing the Mosaic. IPD, London.

Koonce, R. (2001) Redefining diversity: it's not just the right thing to do, it also makes good business sense. Training \& Development, Vol. 12 No. 12, pp. 2232.

Lavaty, S. and Kleiner, B.H. (2001) Managing and understanding the French employee. Management Research News, Vol. 24 No. 3/4, pp. 45-48.

Lawrence, B. S. (1997) The black box of organisational demography. Organisation Science, 8, pp. 1-22.

Martin, J. (1992) Culture in Organisations. New York: Oxford University Press.

Mannix, E. and Neale, M.A. (2005) What difference makes a difference: The promise and reality of diverse groups in organisations. Psychological Science in the Public Interest, 6, pp. 31-55. 
Mavin, S. and Girling, G. (2000) What is managing diversity and why does it matter? Human Resource Development International, Vol. 3 No. 4, pp. 419433.

McDougall, M. (1996) Equal opportunities versus managing diversity another changlenge for public sector management? The International Journal of Public Sector Management, Vol. 9 No. 5/6, pp. 62-72.

McMillan-Capehart, A. (2005) A configurational framework for diversity: socialization and culture. Personnel Review, Vol. 34 No. 4, pp. 488-503.

Milliken, F. J. and Martins, L. L. (1996) Searching for common threads: understanding the multiple effects of diversity in organisational groups. Academy of Management Review, Vol. 21 No. 2, pp. 402-33.

Mills, G., Austin S. and Thomson, D. (2006) Values and value - two perspectives on understanding stakeholders. Proceedings of J oint International Conference on Construction Culture, Innovation, and Management (CCIM), November 2006, Dubai.

Owens, D. A. and Neale, M. A. (1999) The dubious benefit of group heterogeneity in highly uncertain situations: Too much of a good thing? Working paper, School of Business, Vanderbilt University.

Patterson, R. F. (1990) New Expended Webster's Dictionary. P.S.I. \& Associates, Inc., Miami, FL.

Pelled, L. H., Eisenhardt, K. M. and Xin K. R. (1999) Exploring the black box: An analysis of work group diversity, conflict and performance. Administrative Science Quarterly, 44, pp. 1-28.

Sadri, G. and Tran, H. (2002) Managing you diverse workforce through improved communication. Journal of Management Development, Vol. 21 No. 3, 2002, pp. 227-237.

Schein, E. (1984) Coming to see a new awareness of organisational culture. Sloan Management Review, 25 (2), pp. 3-16.

Schwartz, S. H. (1992). Universals in the content and structure of values: Theoretical advances and empirical tests in 20 countries. Advances in Experimental Social Psychology, 25, pp. 1-65. 
Schwartz, S. H., Melech, G., Lehmenn, A., Burgess, S., Harris M., and Owens, V. (2001) Extending the cross-cultural validity of the theory of basic human values with a different method of measurement. Journal of Cross-Cultural Psychology, 32, pp. 519-542.

Schwartz, S. H. and Littrell, R. (2007) Draft Users Manual: Proper Use of the Schwartz Value Survey. Available from: www.crossculturalcentre.homestead.com/DraftManual_SVS_2Feb2007.doc.

Seymen, O. A. (2006) The cultural diversity phenomenon in organisations and different approaches for effective cultural diversity management: a literary review. Cross Cultural Management: An International Journal, Vol. 13 No. 4, 2006.

Sosik, J. J. (2005) The role of personal values in the charismatic leadership of corporate managers: A model and preliminary field study. The Leadership Quarterly, Vol. 16, pp. 221-244

Stark, E. (2001) Valuing diversity: strategic business imperative or HR agenda. Institute of Behavioral and Applied Management Proceedings, pp. 34-39.

Thomas, R.R. (1991) Beyond Race and Gender: Unleashing the Power of Your Total Work Force by Managing Diversity. AMACOM, New York, NY.

Thomas, R. R. (1996) Redefining Diversity. AMACOM, New York, NY.

Watson, W. E., Kumar, K. and Michaelsen, L. K. (1993) Cultural diversity's impact on interaction process and performance: Comparing homogeneous and diverse task groups. Academy of Management J ournal, 36, pp. 590-602.

Williams, K. and O'Reilly, C. (1998) The complexity of diversity: A review of forty years of research. In Gruenfeld, D. and Neale, M. (Eds.), Research on Managing in Groups and Teams (Vol. 20, pp. 77-140). Greenwich CT: JAI Press.

Wilson, E. M. and Iles, P. A. (1999) Managing diversity- an employment and service delivery challenge. The International Journal of Public Sector Management, Vol. 12 No. 1, pp. 27-49.

Zhang, X., Austin, S. A., Glass, J. and Mills, G. (2008) Toward collective organisational values: A case study in UK construction. In press, Construction Management and Economics, Routledge, UK. 